RUNNING HEAD: Can a leader be seen as too ethical?

Can a Leader be Seen as Too Ethical? The Curvilinear Effects of Ethical Leadership

\author{
Jeroen Stouten \\ University of Leuven \\ Marius van Dijke \\ Erasmus University
}

David M. Mayer

Michigan State University

David De Cremer

China Europe International Business School, CEIBS

\author{
Martin C. Euwema \\ University of Leuven
}

Keywords: Ethical leadership, OCB, Deviance

Acknowledgment. This work was supported by STRT1/10/013TBA from the Research Fund of the Katholieke Universiteit Leuven awarded to the first and last author and Innovation grant 42009 from the European Science Fund awarded to the first author. 


\begin{abstract}
Ethical leadership predicts important organizational outcomes such as decreased deviant and increased organizational citizenship behavior (OCB). We argued that due to the distinct nature of these two types of employee behaviors, ethical leadership decreases deviance in a linear manner (i.e., more ethical leadership leading to less deviance), but we expected ethical leadership to reveal a curvilinear relationship with respect to OCB. Specifically, we expected that, at lower levels, ethical leadership promotes OCB. However, at high levels, ethical leadership should lead to a decrease in these behaviors. We also examined a mechanism that explains this curvilinear pattern, that is, followers' perceptions of moral reproach. Our predictions were supported in three organizational field studies and an experiment. These findings offer a better understanding of the processes that underlie the workings of ethical leadership. They also imply a dilemma for organizations in which they face the choice between limiting deviant employee behavior and promoting OCB.
\end{abstract}




\section{Can a Leader be Seen as Too Ethical? The Curvilinear Effects of Ethical Leadership}

Recent ethical failures within organizations such as fraud and corruption highlight the need for ethical leadership. Ethical leadership focuses on leaders as guardians and communicators of ethical standards. Even though there are multiple accounts on ethical leadership, a number of studies have drawn upon Brown and colleagues' (2005) conception of ethical leadership as: "the demonstration of normatively appropriate conduct through personal actions and interpersonal relationships, and the promotion of such conduct to followers through two-way communication, reinforcement, and decision-making” (p. 120). This definition clarifies that ethical leaders act as role models for employees with regard to following procedures or ethical regulations, but they also actively encourage employees to behave in an ethical manner through reward and punishment systems (cf. Treviño, Hartman, \& Brown, 2000). These leaders feel obligated to moral and legal rules (De Hoogh \& Den Hartog, 2008). Although the scientific literature on ethical leadership is relatively new (e.g. Gini, 1998, Brown et al., 2005), scholars have already provided some clear-cut evidence showing that ethical leaders can reduce deviant employee behaviors and promote organizational citizenship behavior (OCB; Mayer, Aquino, Greenbaum, \& Kuenzi, 2012; Mayer, Kuenzi, Greenbaum, Bardes, \& Salvador, 2009; Walumbwa \& Schaubroeck, 2009). In the present paper, we develop and test an argument regarding unintended and undesirable consequences of ethical leadership for important organizational variables. Specifically, we distinguish between consequences of ethical leadership with regard to prohibitions, that is, limiting undesired, deviant behavior from consequences with regard to prescriptions, that is, the encouragement of OCB that is intended to actively support the collective (cf. Smith, Organ, \& Near, 1983; Tyler \& Blader, 2000). We will argue that due to the distinct nature of these two types of employee behaviors, ethical leadership decreases deviance in a linear manner (i.e., more ethical leadership leading to less deviance), but we 
expect ethical leadership to reveal a curvilinear relationship with OCB. Specifically, at lower levels, ethical leadership should promote OCB. However, at high levels, ethical leadership arguably leads to a decrease in these behaviors. Moreover, we also examine the mechanism that we argue to underlie this relation. That is, we propose that followers' perceptions of moral reproach explain the curvilinear relationship of ethical leadership with follower OCB. In other words, we argue that followers perceive leaders who act in highly ethical ways as looking down upon their morality and consider them not being sufficiently moral, which would undermine their motivation to engage in OCB. Similarly though, followers will perceive leaders who don't care about displaying ethical behavior also as looking down upon their morality given that these followers might perceive such leaders as frowning upon their own moral behavior. Hence, followers will also perceive low ethical leaders to morally reproach them because these leaders do not care for morality.

Our research adds to the emerging literature on ethical leadership in at least three ways. First, the behavioral ethics literature often focuses on voluntary positive contributions to the organization and not harming the organization as outcome variables. It operationalizes these concepts usually as OCB and deviance, respectively (Mayer et al., 2009, 2012). Yet, prior work has mostly focused on beneficial aspects of ethical leadership in promoting OCB and in decreasing deviance (Mayer et al., 2009, 2012; Walumbwa \& Schaubroeck, 2009). In contrast to these findings, we examine effects of ethical leadership that are potentially unintended and may have less desirable consequences for organizations and their members. Second, we intend to show that research on ethical leadership should distinguish not harming the organization, such as by refraining from antisocial, unethical behavior as an outcome of ethical leadership, from voluntary extra-role behaviors that actually support the organization, such as OCB. OCB denotes voluntary behaviors as diverse as defending or promoting the organization, helping coworkers, and performing one's tasks beyond the call of duty (e.g. 
Organ, 1988). Third, we will investigate a previously unidentified mechanism that explains why ethical leadership influences employee OCB, that is, employees' perceptions of moral reproach. That is, we examine whether highly ethical but also highly unethical leaders are perceived as looking down upon or judging people's moral values which would explain the effect on OCB (cf. Monin, Sawyer, \& Marquez, 2008). Fourth, in order to be able to generalize our findings to multiple countries, we will test our ideas in different populations (i.e., Europe and the US) using different methodologies (experimental, single and multisource field research).

\section{Ethical Leadership}

Even though ethical behavior is the shared responsibility of the complete collection of organizational stakeholders, it is clear that many initiatives rely heavily on management and hence are dependent on leaders' concern for moral issues. In other words, at the root of many organizational processes stand leaders whose values and interests shape the extent to which they incorporate ethics in their decisions. Gini (1998) described ethical leaders as leaders who use their social power in their decisions, their own actions, and their influence on others in such a way that they act in the best interest of followers and don't enact harm upon them by respecting the rights of all parties (see also Kanungo, 2001). Riggio et al. (2010) focused on “cardinal virtues" to describe the motivations behind leaders' ethical behavior. Yet, rather than focusing on the intent or motivation of ethical leaders, most research on ethical leadership draws on Brown et al.'s (2005) work that defined ethical leadership in terms of behavior.

The literature on ethical leadership is not the first to highlight the importance of ethics for organizational leaders. Influential literatures such as those on transformational (Bass, 1990) and authentic leadership (Walumbwa, Avolio, Gardner, Wernsing, \& Peterson, 2008) have already implied a focus on the importance of ethics. However, ethical leadership can be 
distinguished from authentic leadership as authentic leaders tend to focus on self-awareness and relational transparency rather than mere ethical behavior (Walumbwa et al., 2008).

Ethical leadership also differs from transformational leadership, particularly with regard to the underlying process. That is, ethical leadership contains an important transactional component through which ethical leaders focus on communicating and encouraging ethical conduct rather than being a role model only (Brown et al., 2005). In other words, because of this transactional aspect compliance to ethical standards is expected and discipline and consequences are used for ethical lapses (Treviño, Brown, \& Hartman, 2003).

The process through which ethical leaders influence employees is commonly explained in reference to social learning theory (Brown et al. 2005; Mayer et al., 2009; see Bandura, 1986, for an extensive formulation of social learning theory). This theory argues that people learn specific behaviors by observing a person who is perceived as legitimate in his/her actions. Here, followers observe leaders and take their behavior as a reference. Also in line with social learning theory, ethical leaders hold employees accountable for ethical behavior (Gini, 1998; Treviño et al., 2003). To meet these ethical expectations, in terms of social learning theory, ethical leaders ensure that employees meet ethical expectations not only by functioning as a role model but also by using positive and negative reinforcement. Hence, ethical leaders encourage people to follow rules as mandatory, thus limiting undesirable deviant behaviors (Mayer et al., 2009). Deviance is defined as "voluntary behavior that violates significant organizational norms and, in so doing, threatens the wellbeing of the organization or its members, or both" (Bennett \& Robinson, 2000, p. 349). Given that ethical leaders wish to discourage and negatively reinforce undesirable behavior, we expect that ethical leadership will be negatively related to employees' deviant behavior.

Hypothesis 1: Ethical leadership is negatively related to employees' deviant behavior. 
Many ethical behaviors that are also critical to the long-term functioning of groups and organizations are voluntary in nature. For instance, prosocial behaviors such as OCB have a strong ethical component (Aquino, Freeman, Reed II, Lim, \& Felps, 2009). These behaviors are particularly important to organizations because they allow for flexibility in adapting to challenges faced by the organization to which normative expectations and rules have not yet adapted. Thus, understanding how to motivate OCB is an important challenge for leaders. Consistent with prior work (e.g. Mayer et al., 2009, 2012), we expect that ethical leaders are likely to promote these types of behaviors by their functioning as role models.

In line with social learning theory (Bandura, 1986), we expect employees to feel obliged to comply with the required ethical standards, particularly because ethical leadership also implies reinforcing such desired, minimum level behaviors as it is part of their daily duties (i.e. reduced levels of deviance). Yet, at the same time people may feel that leaders high in ethical standards and behavior are ethically unreachable. Employees may consider that "their own morality pales" in comparison to the leaders' ethical behavior (cf. Monin et al., 2008, p. 13). In fact, employees may perceive ethical leaders to evaluate the legitimacy of their values and call into question their attitudes and behavior (cf. Minson \& Monin, 2012).

Such feelings of being questioned in one's morality and being looked down upon is often seen as insulting and arrogant (Sabini \& Silver, 1982), which can result in the letting go of desirable behavior that is seen as voluntary and goes beyond daily tasks, such as OCB (e.g. Rollins and Thomas, 1979). As employees might perceive that high ethical leaders evaluate the legitimacy of their values, this is expected to undermine OCB. That is, ethical leadership often can be perceived as a social exchange relationship (Mayer et al., 2009) in which both leaders and followers aim to balance costs and benefits (Homans, 1961). Social exchange theory states that employees who feel supported by their organization respond to the experienced support with increased organizational commitment (Rhoades, Eisenberger, \& 
Armeli, 2001). Yet, if ethical leaders are perceived as judging employees' values employees are motivated to restore the balance by refraining from behavior beyond the call of duty, that is, decreased OCB. Because we expect this especially will be the case at low and high levels of ethical leadership, the relation between ethical leadership and OCB is expected to show a curvilinear (rather than a linear) pattern. This leads to the following hypothesis:

Hypothesis 2: Ethical leadership has a negative curvilinear relationship (inverted $U$ shape) with organizational citizenship behavior (OCB).

Above we argued that employees might perceive that ethical leaders judge their values as they cannot keep up with the leaders' values. As such, we argue that followers are likely to perceive the leader who is high in ethical behavior, even when it originates from the best of intentions, as looking down upon their own values (Calhoun, 1989). Employees may perceive such moral reproach and feel that the leader considers them to be morally unequal (Minson \& Monin, 2012). Following from this, we argue that employees will perceive highly ethical leaders as evaluating their morality and perceive high ethical leaders to morally reproach their values more than moderate ethical leaders.

Similar to high ethical leaders, followers may also perceive low ethical leaders to judge their values as followers. That is, in terms of low ethical leadership, employees might feel that this leader does not act in an ethical fashion and thus think the leader looks down on them and trusts their ethicality less. When ethical leadership is low employees feel less satisfied and committed (Brown et al., 2005) and part of it might be because the leader might make you think the (s)he would look down on you in terms of ethics. This might signal to employees that low ethical leaders consider employees' moral principles irrelevant. As such, like high ethical leaders, followers can be expected to perceive low ethical leaders to look down upon their values relative to moderate ethical leaders. Therefore, we hypothesize: 
Hypothesis 3: High and low ethical leaders will be perceived as more morally

reproachful than moderate ethical leaders.

Moreover, given that we expect a curvilinear relationship between ethical leadership, perceptions of moral reproach and $\mathrm{OCB}$, we subsequently examine whether perceptions of moral reproach underlies the curvilinear relation with OCB.

Hypothesis 4: The curvilinear relationship of ethical leadership with organizational citizenship behavior $(O C B)$ will be explained by perceptions of moral reproach.

\section{Overview of the Studies}

We tested our hypotheses in four studies: three field studies and one experimental study. In order to generalize our findings independent of a specific measurement of OCB, we used different OCB measures in Study 1/3, Study 2, and Study 4. Studies 1-3 are field studies and one of the most important challenges in these studies is to ensure that the observed relationships between variables result from meaningful covariation rather than from common method variance (Podsakoff, MacKenzie, Lee, \& Podsakoff, 2003). We took two different measures to limit this bias. In Study 1, we focused on OCB, and collected data from employees as well as their coworkers, thus relying on distinct data sources. In Study 2, we separated the measurement of our dependent and independent variables in time in order to reduce the likelihood of common method bias (Podsakoff et al., 2003). In this study, we again tested for the curvilinear effect of ethical leadership on employee OCB (Hypothesis 2) and this time we also measured employee deviance directed at the organization (Hypothesis 1). In Study 3, we again relied on a multisource design to test the relationship between ethical leadership and employee's deviance (Hypothesis 1) and OCB (Hypothesis 2). Moreover, here we also focused on supervisor-directed deviance in addition to organizational deviance in order to be able to generalize to different types of deviance. As such, our findings are not limited to one specific measurement of deviance. 
Studies 1-3 are field studies that allow us to generalize our findings to organizational contexts. In Study 4, we used an experimental procedure to test our hypothesis regarding deviance (Hypothesis 1) and to examine whether ethical leaders are being perceived to morally reproach people's values (Hypothesis 3 ) and to decrease OCB (Hypothesis 2). This allows us to detect the mechanism of unintended effects of ethical leadership (Hypothesis 4). An experimental approach also suggests the causal path that a specific relationship takes such as in this case how ethical leaders influence people's perceptions of moral reproach as well as OCB and deviance.

Finally, in order to be able to increase possible generalization of our findings we used a multi-country approach for the different studies. We used samples from Belgium, the Netherlands, and the US.

\section{Study 1}

In Study 1 we specifically focused on examining the possibility of a curvilinear relationship between ethical leadership and employee OCB. In order to reduce commonmethod and self-presentation concerns, this study used a multi-source design. Focal employees indicated their supervisor's ethical leadership and coworkers indicated the focal employee's OCB.

\section{Method}

\section{Participants and Procedure}

A total of 280 individuals - 140 focal employees and their matched co-workersparticipated in the study as part of a snowball sampling procedure (response rate: $40 \%$; see e.g., Morgeson \& Humphrey, 2006; Skarlicki \& Folger, 1997; Van Dijke, De Cremer, \& Mayer, \& van Quaquebeke, 2012 for similar procedures). Researchers send out email invitations to employees and requested their participation. Focal employees were instructed to visit a website to complete a survey and to send an electronic survey link to a co-worker 
familiar with their work. Respondents were assured that their responses would remain confidential. We took a number of steps to ensure that the surveys were completed by the correct sources. First, in introducing the study, we told the employees that it was essential for the focal employees and coworker respondents to fill out the correct surveys. Second, when participants submitted their on-line surveys, time stamps and IP addresses were recorded to ensure that the surveys were submitted at different times and with different IP addresses. We found no irregularities in the responses.

Participants were from a variety of different organizations in Flanders (Belgium). The focal employees were $55 \%$ male. The mean age was 39.23 years $(S D=10.32)$. Thirty-four percent had graduated only from high school, and $66 \%$ had a college degree. The respondents worked, on average, for 8.30 years in their current job $(S D=8.37)$.

The co-workers were $44 \%$ male and averaged $38.53(S D=10.73)$ years of age. Thirtyfive percent had graduated only from high school, and $65 \%$ had a college degree. The respondents worked, on average, for 8.39 years in their current job $(S D=8.47)$.

\section{Measures}

All items employed the same five-point rating scale format $(1=$ strongly disagree $; 5=$ strongly agree).

Ethical leadership. We assessed ethical leadership by asking focal employees to respond to the 10-item scale constructed and validated by Brown et al. (2005). Sample items are "My manager disciplines employees who violate ethical standards" and "My manager sets an example of how to do things the right way in terms of ethics" (Cronbach's $\alpha=.91$ ).

$\boldsymbol{O C B}$. Coworkers indicated the focal employee's OCB with Lee and Allen's (2002) eight-item OCB scale. Sample items are: this employee "willingly gives up his/her time to help others who have work-related problems" and "gives up time to help others who have work or nonwork problems" Cronbach's $\alpha=.85$ ). 


\section{Analyses}

In order to test our hypotheses regarding the curvilinear effects of ethical leadership we calculated the square of ethical leadership. Regressing control variables and ethical leadership in step 1 and the squared ethical leadership variable in step 2 allows for examining the curvilinear relationship. We tested whether the squared variable of ethical leadership explains significant variance in the dependent variable beyond the variance explained by the linear term this provides evidence for the curvilinear relationship (Cohen, Cohen, Aiken, \& West, 2002). Furthermore, we calculated the inflection point - a maximum or a minimum depending on the shape of the curve - of the curvilinear pattern. ${ }^{1}$

\section{Results}

\section{Measurement Model.}

Before testing our hypotheses, we conducted CFAs to test our measurement model at the item level to determine whether scale items adequately indicate their intended underlying constructs (Anderson \& Gerbing, 1988; Bandalos \& Finney, 2001). The initial measurement model had two latent factors and 18 indicators (i.e., ethical leadership and OCB). We estimated a model with two latent variables (ethical leadership and OCB) as well as a onefactor model in which all items loaded onto one factor. We also fitted a three-factor model, which included the two latent variables together with a common method factor that was uncorrelated to the theoretically derived factors (cf. Podsakoff et al., 2003). To judge the goodness of fit of the measurement model, we relied on the root-mean-square error of approximation (RMSEA, Steiger, 1990), the comparative fit index (CFI, Bentler, 1990), and the parsimony adjusted comparative fit index PCFI; Mulaik et al., 1989).

The two-factor model fitted the data quite well $\left(\chi^{2}(136)=249.57\right.$, RMSEA $=.079$ $(90 \% \mathrm{CI}=.063-.094), C F I=.93, P C F I=.83)$. The fit of the one-factor model was clearly insufficient $\left(\chi^{2}(136)=861.18, R M S E A=.199(90 \% \mathrm{CI}=.187-.212), C F I=.54, P C F I=\right.$ 
.48). The three-factor model also fitted the data well $\left(\chi^{2}(118)=170.24\right.$, RMSEA $=.057(90 \%$ $\mathrm{CI}=.037-.076), C F I=.97, P C F I=.75) . C F I$ and $R M S E A$ suggest a slightly better fit for the three-factor model. However, PCFI (i.e., which explicitly corrects for model complexity) is clearly lower for the three- than the two-factor model. Hence, common method error does not appear to play a significant role in our data. Furthermore, the fact that our main hypothesis regards a multiplicative effect (which is not affected by common method error; Evans, 1985) further increases our confidence that we can validly interpret the findings from these data. Hypothesis test.

Table 1 shows descriptive statistics and intercorrelations. Table 2 shows the regression results. In line with our expectations, the squared ethical leadership term explained variance in addition to the linear ethical leadership term for $\operatorname{OCB}(\beta=-1.73, p<.05$; Figure 1$)$. More specifically, the relationship of OCB with ethical leadership showed an inverted-U shape, indicating that at low levels ethical leadership had a positive relation with OCB, but at high levels of ethical leadership OCB decreased (with a maximum at ethical leadership $=4.07)^{2}$. This finding supports Hypothesis 2.

\section{Discussion}

In a multi-source field study, results showed that ethical leadership has a curvilinear relationship with OCB. Hence, even though OCB increased at low to moderate levels it declined after the inflection point at high levels of ethical leadership. This provided some first evidence for our hypotheses.

\section{Study 2}

Study 2 aimed to replicate and extend the results of Study 1 by focusing on a number of additional outcome variables. Specifically, we included measures of employees' organizational deviance. We expected that ethical leadership has a negative linear relationship with deviance, but an inverted U-shaped relationship with employee OCB. 


\section{Method}

\section{Participants and Procedure}

We invited 834 employees from a variety of occupations in the Netherlands to participate in the study. To make our analyses less sensitive to common-method bias (Podsakoff et al., 2003) we separated the measurement of the dependent and independent variables in time. A total of 676 employees responded at the first measurement point, and 410 employees responded again at the second measurement point, three months later. Of the employees who completed both surveys, 264 were male (63.8\%). The mean age was 44 years, $32.1 \%$ had a college degree and the respondents worked on average 5.73 years in their organization.

\section{Measures}

All items employed the same five-point rating scale format $(1=$ strongly disagree $; 5=$ strongly agree).

Time 1 measures. At time 1 we assessed demographic variables. We also measured ethical leadership with the same scale as in Study 1 (Cronbach's $\alpha=.92$ ).

Time 2 measures. We measured organizational deviance with Bennett and Robinson's (2000) 12 item scale. Sample items include, "I have taken property from work without permission" and "I come in late without permission" Cronbach's $\alpha=.90$ ).

We used Moorman and Blakely's (1995) 19-item instrument to measure OCB. Example items are: "I motivate others to express their ideas and opinions" and "I voluntarily help new employees to settle into the job" (Cronbach's $\alpha=.88$ ).

\section{Results}

\section{Measurement Model.}

Like in Study 1, we first conducted CFAs to test our measurement model at the item level. The initial measurement model had six latent factors and 41 indicators (i.e., ethical 
leadership, organizational deviance, and the four OCB dimensions). We estimated a model with these six latent variables as well as a one-factor model in which all items loaded onto one factor. We also fitted a seven-factor model, which included the six latent variables together with a common method factor that was uncorrelated to the theoretically derived factors. To judge the goodness of fit of the measurement model, we relied on the same indices as in Study 1.

The six-factor model (with ethical leadership, deviance and OCB as latent variables) did not fit the data very well $\left(\chi^{2}(765)=2027.67, R M S E A=.063(90 \% \mathrm{CI}=.060-.067), C F I\right.$ $=.85, P C F I=.79)$. The fit of the one-factor model was clearly insufficient $\left(\chi^{2}(779)=\right.$ 6234.62, RMSEA $=.130(90 \% \mathrm{CI}=.127-.133), C F I=.34, P C F I=.32)$. The seven-factor model fitted the data best $\left(\chi^{2}(724)=1663.30, R M S E A=.056(90 \% \mathrm{CI}=.053-.060), C F I=\right.$ $.89, P C F I=.78)$. This suggests that common method variance may play a role in our data. This is not surprising given that the four OCB dimensions and organizational deviance were indexed by the same focal employee at the same point in time. Yet, it is also not problematic because method variance that is shared between the different depended variable dimensions does not compromise the test of our hypotheses regarding linear and curvilinear relations between the independent variable and the various dependent variables.

To investigate the reason for the less than optimal fit of the six and seven factor models (particularly for the $C F I$ ), we considered which of the two dependent variables (i.e., OCB or organizational deviance) most clearly compromised the model. In order to do this, we compared a series of models that contained the independent variable (ethical leadership) and one dependent variable at a time (i.e., either the OCB dimensions, or organizational deviance).

We first fitted a measurement model with five latent factors (i.e., ethical leadership and the four OCB dimensions). The five-factor model showed a less than desirable fit $(\chi$ 
$\left.{ }^{2}(368)=1096.90, R M S E A=.069(90 \% \mathrm{CI}=.065-.074), C F I=.87, P C F I=.79\right)$. However, the six-factor model (adding a common method factor to the five-factor model), fitted the data well $\left(\chi^{2}(339)=637.85, R M S E A=.046(90 \% \mathrm{CI}=.041-.052), C F I=.95, P C F I=.79\right)$.

We subsequently fitted a measurement model with two latent factors (i.e., ethical leadership and organizational deviance). The two-factor model showed insufficient fit to the data $\left(\chi^{2}(209)=1144.33, R M S E A=.104(90 \% \mathrm{CI}=.098-.110), C F I=.81, P C F I=.74\right)$. The three-factor model (adding a common method factor to the two-factor model), fitted the data better, and almost acceptable according to most accepted cutoff points for fit criteria $\left(\chi^{2}(189)\right.$ $=719.33$, RMSEA $=.082(90 \% \mathrm{CI}=.076-.089), C F I=.89, P C F I=.73)$.

In sum, these analyses showed that the model containing the four OCB dimensions and ethical leadership showed a good fit to the data. Common method variance plays a role in this model, but this is not surprising given that the OCB items were all assessed by the same focal employee at the same point in time. The model with ethical leadership and organizational deviance showed a less impressive but still almost sufficient fit. Given these results, and because our most important predictions were about the curvilinear effects of ethical leadership on OCB, we decided to proceed with testing our hypotheses. Hypotheses tests.

Table 3 shows descriptives and intercorrelations. Table 4 shows the results of the regression analyses. Results show that higher ethical leadership was associated with reduced deviance. The squared ethical leadership term was, however, not related to deviance, revealing no evidence for a curvilinear relationship between ethical leadership and employee deviance. This supports Hypothesis 1.

Further, ethical leadership was significantly positively related to OCB. Entering the squared ethical leadership term resulted in variance explained in addition to the linear ethical leadership term for OCB. More specifically, the relationship of OCB with ethical leadership 
showed an inverted-U shape. At lower levels, ethical leadership was positively related to OCB but at higher levels, the relationship was negative. ${ }^{2}$ This supports Hypothesis 2.

\section{Discussion}

Results of Study 2 were consistent with the findings of Study 1 in which we showed a curvilinear effect of ethical leadership and OCB. Even though we used a different method and a different measure of OCB we found consistent evidence that at lower levels of ethical leadership it was positively associated with OCB but at higher levels of ethical leadership, it was negatively related to OCB. Moreover, Study 2 also showed that ethical leadership is negatively related to employee deviance, suggesting that ethical leadership has differential results with respect to stimulating positive (OCB) and decreasing negative (deviance) employee behavior.

\section{Study 3}

Study 3 aimed to extend the results of Study 2 by assessing an additional deviance measure, that is, supervisor directed deviance (in addition to organization directed deviance). This would allow us to generalize our findings more independently from specific measures. Furthermore, in order to generalize to different samples data were collected in a different country (US). Similar to Study 1, this study used a multi-source design. Focal employees indicated their supervisor's ethical leadership and coworkers indicated the focal employees' deviance and OCB.

\section{Method}

\section{Sample and Procedure}

A total of 336 individuals - 168 focal employees and their matched co-workersparticipated in the study as part of a snowball sampling procedure (e.g., Grant \& Mayer, 2009; Morgeson \& Humphrey, 2006; Skarlicki \& Folger, 1997). Researchers sent an electronic message to 349 business major students in the US and asked them to help with a study for 
extra credit. Students who worked at least 20 hours per week in a job were allowed to participate in the study; if they did not, they were asked to invite a family member or close other to complete the survey. A total of 168 focal employees participated (a response rate of $48 \%$ ). We used the same procedure as in Study 1. That is, focal employees were instructed to visit a website to complete a survey, and to send an electronic survey link to a co-worker familiar with their work. Here as well, we found no irregularities in the responses.

Participants were from a variety of different organizations in the Southeast U.S., including technology, government, insurance, financial, food service, retail, manufacturing, and medical organizations. The focal employees were $48 \%$ male and 65\% Caucasian (19\% Hispanic, 4\% African-American, 3\% Latino Latina, 1\% biracial, and 5\% Asian American; 3\% indicated "another racial background"). The mean age was 24.09 years $(S D=5.76)$. Four percent of the respondents had only lower education (high school), 55\% had some college experience, and $42 \%$ had a college degree. The respondents worked, on average, for 2.34 years with their current organization $(S D=2.14)$. They worked on average for 1.65 years with their current supervisor $(S D=1.59)$.

The co-workers were $40 \%$ male. Sixty-seven percent were Caucasian (13\% Hispanic, 8\% African-American, 5\% Latino/Latina, and 5\% Asian American; 1\% indicated "another racial background"). Fourteen percent of the co-workers indicated having only lower education (high school), $42 \%$ had some college experience, $33 \%$ had a college degree, $5 \%$ were in graduate school and 5\% had a master degree. They averaged $27.5(S D=9.66)$ years of age with 3.49 years of experience working in their organizations $(S D=3.81)$.

\section{Measures}

All items employed the same seven-point rating scale format ( 1 = strongly disagree; 7 = strongly agree . 
Ethical leadership. Focal employees indicated their supervisor's ethical leadership by responding to the same scale that was also used in Study 1 and 2 (Cronbach's $\alpha=.95$ ).

Deviance. Coworkers indexed the focal employee's organizational deviance with the same scale that was also used in Study 2 (Cronbach's $\alpha=.94$ ). Coworkers also indexed the focal employee's supervisor-directed deviance with Mitchell and Ambrose's (2007) 10 item scale. Sample items include "This employee gossiped about my supervisor," and "This employee swore at my supervisor" (Cronbach’s $\alpha=.94)$.

OCB. Coworkers indexed the focal employee's OCB with Lee and Allen's (2002) eight item OCB scale (Cronbach's $\alpha=.96)$.

\section{Results}

\section{Measurement Model.}

Like in Study 1 and 2, we first conducted CFAs to test our measurement model at the item level. The initial measurement model had four latent factors and 40 indicators (i.e., ethical leadership, organizational deviance, supervisor directed deviance, and OCB). We estimated a model with these four latent variables as well as a one-factor model in which all items loaded onto one factor. We also fitted a five-factor model, which included the four latent variables together with a common method factor that was uncorrelated to the theoretically derived factors. To judge the goodness of fit of the measurement model, we relied on the same indices as in Study 1 and 2.

The four-factor model did not fit the data well $\left(\chi^{2}(734)=1953.16, R M S E A=.123\right.$ $(90 \% \mathrm{CI}=.116-.130), C F I=.76, P C F I=.71)$. The fit of the one-factor model was clearly insufficient $\left(\chi^{2}(742)=3702.16, R M S E A=.190(90 \% \mathrm{CI}=.184-.197), C F I=.41, P C F I=\right.$ .39). The five-factor model (adding a common method factor to the four-factor model), fitted the data best, but the fit of this model was still clearly below accepted standards $\left(\chi^{2}(695)=\right.$ 1620.23, RMSEA $=.110(90 \% \mathrm{CI}=.103-.117), C F I=.82, P C F I=.73)$. 
To investigate the reason behind the less than optimal fit of the four and five factor models, we proceeded by considering which of the dependent variables compromised model fit most significantly.

A model without organizational deviance in the analyses showed unacceptable fit $(\chi$ $\left.{ }^{2}(347)=794.21, R M S E A=.108(90 \% \mathrm{CI}=.098-.118), C F I=.86, P C F I=.79\right)$. The same model but now with also a method factor as part of the analysis showed acceptable fit $(\chi$ $\left.{ }^{2}(320)=622.76, R M S E A=.093(90 \% \mathrm{CI}=.082-.104), C F I=.91, P C F I=.77\right)$.

A model without supervisor directed deviance showed unacceptable fit to the data $(\chi$ $\left.{ }^{2}(420)=934.50, R M S E A=.110(90 \% \mathrm{CI}=.100-.119), C F I=.84, P C F I=.77\right)$. The same model but now with also a method factor as part of the analysis showed improved, but still barely acceptable fit $\left(\chi^{2}(372)=766.55, R M S E A=.098(90 \% \mathrm{CI}=.088-.108), C F I=.88\right.$, $P C F I=.75)$.

A model without OCB showed clearly unacceptable fit $\left(\chi^{2}(461)=1434.50, R M S E A=\right.$ $.139(90 \% \mathrm{CI}=.130-.147), C F I=.75, P C F I=.70)$. The same model but now with also a method factor as part of the analysis showed also unacceptable fit $\left(\chi^{2}(430)=1111.78\right.$, $R M S E A=.120(90 \% \mathrm{CI}=.111-.129), C F I=.82, P C F I=.71)$.

A model without supervisor directed deviance and organizational deviance (and thus only OCB and ethical leadership included) fit the data well $\left(\chi^{2}(134)=233.09\right.$, RMSEA $=.082$ $(90 \% \mathrm{CI}=.064-.099), C F I=.95, P C F I=.83)$. The same model but now with also a method factor as part of the analysis showed clearly acceptable fit $\left(\chi^{2}(116)=163.05, R M S E A=.061\right.$ $(90 \% \mathrm{CI}=.037-.082), C F I=.98, P C F I=.74)$.

In sum, like in Study 1, the model that contains our primary dependent variable (OCB) together with the independent variable (ethical leadership) shows a superior fit to the data, relative to all other models. Furthermore, this model also shows little evidence for the operation of common method variance: CFI and RMSEA are slightly higher for the model 
containing a method factor, but PCFI (which explicitly "punishes" model complexity) is clearly lower (and, in fact, unacceptably low) in the model containing a method factor, relative to the model that does not contain this factor. This is not surprising given that ethical leadership and OCB were indexed by two different sources.

Furthermore, like in Study 2, including deviance in the model resulted in clearly lowered fit. We thus decided to proceed with our hypotheses tests, which are mostly concerned with the curvilinear effects of ethical leadership on active cooperative behaviors like OCB. We will also use deviance as a dependent variable in our analyses, but the reader should interpret these analyses with more caution.

\section{Hypotheses tests.}

Table 5 shows descriptive statistics and intercorrelations. Regression results are presented in Table 6. These analyses showed that the linear term of ethical leadership significantly predicted supervisor- as well as organization-directed deviance such that deviance was lower when ethical leadership was higher. We found no evidence for a curvilinear relationship between deviance and ethical leadership. This supports Hypothesis 1 .

The linear effect of ethical leadership was also significantly related to OCB. Furthermore, after entering the squared ethical leadership term, it explained additional variance and revealed significant relationships for OCB. More specifically, the relationship for OCB showed an inverted-U pattern (see Figure 3). ${ }^{2}$ This supports Hypotheses 3.

\section{Discussion}

Study 3 again showed consistent results with the previous studies by showing a curvilinear relation of ethical leadership and OCB. Moreover, this study replicated the previous findings in a different country (US) which enables us to generalize findings across different sample characteristics. Moreover, like Study 2, results showed a linear negative relation of ethical leadership and employee deviance. Here, we extended organizational 
deviance with supervisor-directed deviance for which ethical leadership also showed a negative linear relation.

\section{Study 4}

In a fourth study, we wished to examine the unintended negative effect of high ethical leadership on deviance and OCB. Further, we focused on the underlying process of perceptions of moral reproach (Monin et al., 2008) to be able to explain the relation of ethical leadership and OCB. A vignette experiment was used, which provides the possibility to increase internal validity and to infer causality (e.g Burris, 2012).

\section{Method}

\section{Participants and Procedure}

Eighty-seven undergraduate business students from a European university participated voluntarily. Participants were 50.6\% male and on average 20 years old $(S D=2.16)$. They had an average work experience of 2.5 years $(S D=2.13)$. After their arrival in the lab, they were welcomed by the experimenter. All instructions were given on paper. We employed a between-subject design by assigning our participants on a random basis to one of three conditions of ethical leadership (low, moderate, or high). Participants were asked to place themselves in the situation of an employee in a company and were given a description of their supervisor. Then, our manipulation of ethical leadership commenced. This manipulation was based on the conception of ethical leadership by Brown et al. (2005). In the low ethical leadership condition, their supervisor was described as a person who does not make fair and balanced decisions:

"René is a supervisor who doesn't believe in doing the "right" thing in terms of ethics. That is why René often makes compromises regarding ethics. Many will describe René as a person who never makes ethical decisions. René never does what he says regarding ethics and hardly ever consistently acts according to own ethical values if it comes to taking decisions. 
This is the reason that René tolerates violations of ethical standards. When faced with dilemmas at work, René says "get it done by any means."

In the high ethical leadership condition, their supervisor was described as a person who makes fair and balanced decisions, a person of integrity, who walks the talk, and someone who does not tolerate any violation of ethical standards:

"René is a supervisor who very strongly believes in doing the "right" thing in terms of ethics without making compromises. René likes to be seen as a person who always takes ethical decisions. René always does what he says regarding ethics and consistently acts according to own ethical values if it comes to taking decisions. This is the reason that René does not tolerate any violations of his ethical standards. When faced with dilemmas at work, René asks "what is the right thing to do?"

In the moderate ethical leadership condition, their supervisor is described as a person who is concerned with ethics:

"René is a supervisor who believes in doing it "right" in terms of ethics. That is why René (depending on the exact situation) evaluates the necessity to make a compromise or not in terms of ethics. Many like to see René as a person who considers it important to make ethical decisions (but not at all costs and consequences). René tries to walk the talk and aims to be consistent with everyone's ethical values if it comes to taking decisions. When faced with dilemmas at work, René asks "what is the right and ethical thing to do in this particular situation?"

\section{Measures}

All items were assessed using a 7-point likert scale ranging from 1 (not at all) to 7 (very much so). First, we measured participants' perceptions of moral reproach (cf. Minson \& Monin, 2012). Participants were asked to what extent they considered the leader to look down upon them, to be moral equals (reversed), and to trust them for their ethical judgment 
(Cronbachs' alpha =.66). Second, participants' deviance (cf. Bennett \& Robinson, 2000) was measured by asking for the extent they would come in late at work without notice and refuse to pass on information to others in the situation described in the vignette (Cronbachs' alpha $=$ .79). Finally, interpersonally oriented OCB (cf. Moorman \& Blakely, 1995) was measured by asking participants whether they would be motivated and willing to help their coworkers (Cronbachs' alpha $=.91)$ if they worked for the supervisor described in the vignette.

\section{Results}

In order to test for the effectiveness of the manipulation of ethical leadership independent of the measurement of perceptions of moral reproach and OCB we used a different sample of participants (i.e., to avoid demand characteristics). Eighty-five undergraduate students participated voluntarily in a between-subject design in which ethical leadership was manipulated (low, moderate, and high) using the exact same manipulations as those used in the main study. We measured the extent to which participants considered the leader to be ethical with four items: "to what extent to you consider this leader to be "ethical", “true to his/her own values", “moral”, and "principled” (Cronbachs' alpha =.96). An ANOVA on the extent to which participants considered the leader to be ethical showed a significant effect, $F(2,82)=156.74, p<.001$. Post-hoc tests showed that low ethical leaders $(M=2.14 ; S D=.94)$ were perceived to be lower on ethicality than moderate $(M=5.18 ; S D$ $=.79), p<.001$, and high ethical leaders $(M=5.68 ; S D=.69), p<.001$. Moderate ethical leaders were also found to be significantly lower on ethicality than high ethical leaders, $p<$ .05. These results show that the manipulation of ethical leadership was successful.

To test our first hypothesis concerning the relation of ethical leadership and deviance we performed an ANOVA, which revealed a significant effect for ethical leadership, $F(2,84)$ $=11.46, p<.001$. Post-hoc tests showed that low ethical leadership $(M=3.22 ; S D=1.56)$ resulted in more deviance than moderate ethical leadership $(M=1.87 ; S D=.59), p<.001$, 
and high ethical leadership $(M=2.16 ; S D=1.07), p<.001$. Moderate and high ethical leadership did not significantly differ from each other, $p>.30$. This offers support Hypothesis 1.

An ANOVA showed a significant effect for ethical leadership on perceptions of moral reproach, $F(2,84)=24.20, p<.001$. Post-hoc tests showed that moderate ethical leadership $(M=2.62 ; S D=.87)$ was perceived as lower on perceptions of moral reproach than high ethical leadership $(M=3.80 ; S D=1.10), p<.001$, and low ethical leadership $(M=4.57 ; S D=$ 1.27), $p<.001$. High and low ethical leadership also significantly differed from each other, $p$ $<.05$. Given these differences between the different levels, we tested for the curvilinear relation using polynomial contrasts. Results showed that the effect of ethical leadership on perceptions of moral reproach supports a curvilinear pattern (95\% CI $[.88,1.68])$. This offers support for Hypothesis 3.

Similarly, for OCB an ANOVA showed a significant effect for ethical leadership, $F(2$, $84)=12.56, p<.001$. Post-hoc tests showed that moderate ethical leadership $(M=5.15 ; S D=$ .88) resulted in higher OCB than high ethical leadership $(M=4.30 ; S D=1.36), p<.001$, and low ethical leadership $(M=3.33 ; S D=1.81), p<.024$. Further, high and low ethical leadership also differed significantly, $p<.05$. Polynomial contrasts here also showed that the effect of ethical leadership on OCB showed a curvilinear pattern (95\% CI [-1.60, -.58]). This supports Hypothesis 2.

Furthermore, in order to test for mediation on OCB, an ANCOVA with perceptions of moral reproach as a covariate showed a significant effect for perceptions of moral reproach $F(1,83)=22.54, p<.001$, but ethical leadership became nonsignificant, $F(2,84)=1.59, p>$ .20. A Sobel-test showed that the indirect effect was significant $($ Sobel $=2.23, p<.05)$. Bootstrap mediation tests (Preacher \& Hayes, 2008) also showed that perceptions of moral reproach mediated the effect of ethical leadership on OCB. Specifically, perceptions of moral 
reproach mediated on low $(95 \%$ CI $[.88,2.77])$, moderate $(95 \%$ CI $[.09, .50])$, and high ethical leadership (95\% CI [-2.16, -.56]). This supports Hypothesis 4.

\section{Discussion}

Consistent with the previous studies, our results showed that high ethical leaders decreased participants' deviance in comparison to low ethical leaders. Further, results pointed out that high relative to moderate ethical leaders were perceived as morally reproaching participants' values and morality. Further, we also showed that low ethical leaders were perceived to morally reproach participants' values more than moderate ethical leaders. Similar to high ethical leaders, people may have felt that low ethical leaders looked down upon their principles and values possibly because employees needed to downplay their ethical behavior to reach the leader's low normative standards. This study also revealed that ethical leadership showed a curvilinear pattern for people's OCB. Moderate ethical leaders were found to encourage OCB more than low and high ethical leaders. Moreover, perceptions of moral reproach explained (mediated) this pattern on OCB. In relation to the previous studies that tested our hypotheses in an organizational sample, this study tested and showed the causal relations.

\section{General Discussion}

Our research - at least to our knowledge - is the first to explicitly address unintended negative effects of ethical leadership. Across three studies, using different methodologies (i.e., experimental, single and multisource studies) and conducted in three different countries (i.e., Belgium [Study 1 and 4], the Netherlands, [Study 2], and the US [Study 3), we showed that ethical leadership is linearly related to employee deviance. In line with prior work, deviance was shown to be lower at higher levels of ethical leadership (e.g. Mayer et al., 2009). However, ethical leadership revealed an inverted U-shaped relationship with OCB. In other words, at lower levels of ethical leadership OCB increases, whereas at higher levels OCB 
decreases. Moreover, we could show that perceptions of moral reproach underlie this curvilinear relation. In the following sections, we will discuss these findings.

\section{Theoretical Implications}

Our research adds to the emerging literature on ethics and leadership in at least three ways. First, we show unintended effects of ethical leadership that are potentially consequential to organizations: That is, employees respond to highly ethical leaders with lower voluntary cooperative behaviors. Cooperative employee behaviors like OCB's are critical for sustained, long term organizational effectiveness (Podsakoff, Whiting, Podsakoff, \& Blume, 2009). Even though previous research illustrated the positive and constructive effects of ethical leadership, specifically also with regard to OCB, we argued and showed that high ethical leadership has a potential unintended effect for people's OCB's. Future research is needed to examine whether this finding can be extended to other employee behaviors.

Second, we showed that ethical leadership differentially encourages behavior that reflects avoidance of deviant behavior from actively promoting the interests of the organization and its members by displaying OCB. Consistent with previous research (Mayer et al., 2009, 2012) ethical leadership was successful in reducing deviant behavior. However, employees find it much harder to invest energy in extra-role behavior, such as OCB. Such behaviors have been shown to require extra effort and an intrinsic motivation to support the organization (Tyler \& Blader, 2003; Zapata-Phelan et al., 2008). Because OCB is largely voluntary behavior, it could be easily reduced, and hence, more likely to suffer if employees perceive leaders to be highly ethical. As such, we add to the literature by showing that ethical leadership both enhances avoiding deviant behavior but at the same time reduces active promotion of the organization's and employees' interests.

Third, we also clarify the process by which ethical leadership influences OCB. More specifically, prior work has stressed the role of social learning processes, noting that ethical 
leaders function as role models and that they also discipline unethical follower behaviors. The present research clarifies the importance of an additional process. Specifically, we argued that if employees perceive leaders as highly or lowly ethical this undermines the effectiveness of the leader as a role model. Employees, in fact, consider such leaders as less attractive role models because they feel morally reproached by these leaders. And this, in turn, explains why employee OCB is highest at moderate levels of ethical leadership (see e.g. Calhoun, 1989; Minson \& Monin, 2012; Schminke, Ambrose, \& Neubaum, 2005). Hence, we also add to the work on moral reproach by applying some of its findings to leadership research.

\section{Practical Implications}

Decreasing employee deviance is an important function of ethical leadership because deviant and antisocial employees hamper effective employee functioning and they can also form a clear threat to the organization's image (Detert, Treviño, Burris, \& Andiappan, 2007). Especially in times when organizations go through financial hardship, ethical leaders can bring guidance and in their modeling they may comfort employees and clarify what is appropriate behavior. At the same time, cooperative employee behaviors like OCB have shown to be crucial for the sustained, long term effectiveness of organizations (Podsakoff \& MacKenzie, 1994; Walz \& Niehoff, 1996). The present results thus strongly suggest that organizations face a dilemma between rooting out unethical employee behavior by displaying high levels of ethical leadership and promoting positive, cooperative behaviors, which are lowered at high levels of ethical leadership.

As employees consider that high ethical leaders look down upon them, it thus seems important for ethical leaders not to come across as morally judging employees. In order to overcome the negative effect of high levels of ethical leadership on OCB, ethical leaders may express their recognition of employees' values and respectfully approach employees' behavior. As such, employees feel the leader cares and undertakes efforts to help them behave 
ethically in their job. Moreover, by doing so, ethical leaders may also 'close the gap' with regard to employees' perceptions of their own and their leaders' morality (e.g. Jordan et al., 2013). Further, leaders specifically not only discuss expected ethical standards with employees but also discuss how these employees feel about the application of these behaviors in their daily work. This can, for example, be done by allowing employees to voice their opinion on the enactment of ethics in the workplace (van Prooijen, 2009). Providing employees with voice might actually enhance their closeness with the leader and foster their need to belong (Tyler \& Blader, 2003) which might decrease the (moral) distance between employees and the leader thereby creating less defensive circumstances.

\section{Strengths and Limitations}

One important strength of the present research is our reliance on a multi-method approach in order to address both internal and external validity. That is, in Study 4, by using an experimental design we were able to suggest causal conclusions about the effect of ethical leadership on OCB. In fact, to our knowledge we were the first to test for the causal relation of ethical leadership with OCB. Previous research also established using correlational research that ethical leadership positively relates to OCB (Mayer et al., 2009) and here we largely replicate this pattern. Further, Studies 1-3 using both multi-source and longitudinal methodologies in different countries allowed us to test our predictions in organizations with employee samples. Moreover, we used different operationalizations of OCB and deviance in order to examine whether the expected relations are not dependent on a specific measurement. This makes us more confident in the generalizability of our findings to actual working populations.

Of course, we realize that all four studies, when looked at in isolation have limitations and strengths: In Study 2 we separated the measurement of the independent and dependent variables in time. This is a well-known and effective way to reduce common method variance 
concerns (Podsakoff et al., 2003). Furthermore, Study 2 had employees from a large variety of different occupations as respondents as such decreasing external validity concerns. Yet, self-reports of positive and negative behaviors may not always be valid, for instance as a result of social desirability biases. Even though social desirability bias can never be ruled out entirely, a multisource design (which we used in Study 1 and 3) has been documented to decrease common-method bias (Podsakoff et al., 2003). Therefore, we applied a multisource design in Study 1 and 3 in which focal employees indicated their supervisor's level of ethical leadership and coworkers indicated the focal employee's deviance and voluntary behavior. Study 3, in itself also has limitations: The population consisted of working students (albeit students who work for at least 20 hours each week), which may limit the generalizability of these findings. However, Study 1 using the same multisource method did use fulltime employees. Yet, we argue that the studies should not be considered in isolation. When considered as a set, a clear strength of the current research is the consistency between the different studies, in terms of the different designs (i.e., experimental, single and multisource) and in terms of different populations from which our samples were drawn (Europe and the US).

One limitation of the field studies that should be recognized is that CFA did not always show acceptable fit for the models containing ethical leadership, OCB and deviance. Including a method factor usually improved model fit, which points at the existence of common method variance in our data. This is in itself not surprising or harmful given that our dependent variables (i.e., the various dimensions of OCB and deviance) were measured at the same point in time and indexed by the same source. More fine grained analyses showed that it is particularly deviance that harms model fit. We can only speculate about why this is the case. One reason may be found in the relatively low incidence rate of behaviors that are indexed by the deviance items (e.g., theft, insulting others), which leads to strongly skewed 
response distributions on the deviance variables. Nevertheless, our conclusions regarding the linear effect of ethical leadership on deviance should be considered with more caution than our primary result, that is, that ethical leadership has a curvilinear effect on OCB.

\section{Future Directions}

We realize that our focus on perceptions of moral reproach as a mediating mechanism does not imply that other mediating processes are irrelevant. An alternative to the mechanism of perceptions of moral reproach might be that displaying OCB is just too costly. That is, high ethical leaders might increase the cost of adhering to ethical standards (i.e., behaving in a nondeviant manner) to such an extent that employees would find it hard to carry out their positive duties (such as engaging in OCB). Hence, the cost of ethical compliance might have a severe impact on employees' resources that allow them to engage in OCB. In philosophy, Kant (1785/1983) made a similar distinction arguing that negative duties (e.g., avoiding deviant behavior) should receive a priority above positive duties (e.g., engaging in $\mathrm{OCB}$ ) as there might be alternative ways to fulfill those positive duties. Future research might turn to examining whether employees are less likely to show OCB because it is too costly.

Following up on this, ethical leaders need not necessarily have the intent to discourage employees' OCB, given their inherent focus on their own and others ethical inclination. Hence, more research is needed to examine when ethical leadership may be positive for employees' OCB and under which conditions it will turn around and become a liability. This will help us understand in more detail how ethical leaders more effectively may guide employees in encouraging not only negative duties but also positive duties.

Furthermore, we showed that perceptions of moral reproach explained the relation of ethical leadership and OCB. Yet, moral reproach is less relevant for explaining the relation of ethical leadership and deviance. One of the key aspects of ethical leaders is that they use reinforcement to discipline deviant behavior. As high ethical leaders would use reinforcement 
the relation of ethical leadership and deviance is linear rather than curvilinear which would make the role of moral reproach for deviance less likely ${ }^{3}$. Indeed, ethical leaders encourage people to follow rules as mandatory, thus limiting undesirable deviant behaviors (Mayer et al., 2009). Future research might look at whether the relation with deviance indeed can be explained by mechanisms of reinforcement.

\section{Conclusions}

Ethical leaders have been described as being "tenacious, steadfast, and uncompromising" (Treviño et al., 2003, p. 18) suggesting their intolerance for deviant behaviors. Decreasing such behaviors is an important function of ethical leadership because deviant employees form a clear threat to the organization's functioning and image. The present results suggest that organizations face a dilemma between rooting out unethical employee behavior and promoting positive, cooperative behaviors. This may form a challenging dilemma for leaders to solve. Yet, at the very least leaders should be aware of the differential effects that their focus on ethics has on follower's deviant as compared employee OCBs. 


\section{References}

Anderson, J., \& Gerbing, D. (1998). Structural equation modeling in practice: A review and recommended two-step approach. Psychological Bulletin, 103, 411-423.

Aquino, K, Freeman, D., Reed, A. II., Lim, V. K. G., Felps, W. (2009). Testing a social cognitive model of moral behavior: The interaction of situational factors and moral identity centrality. Journal of Personality and Social Psychology, 97, 123-141.

Aquino, K., \& Reed, A. II. (2002). The self-importance of moral identity. Journal of Personality and Social Psychology, 83, 1423-1440.

Bandalos, D. L., \& Finney, S. J. (2001). Items parceling issues in structural equation modeling. In G. A. Marcoulides \& R. S. Schumaker (Eds.), New developments and techniques in structural equation modeling. Mahwah, NJ: Erlbaum.Bandura, A. (1986). Social foundations of thought and action: A social cognitive view. Englewood Cliffs, NJ: Prentice-Hall.

Bass, B. M. (1999). Two decades of research and development in transformational leadership. European Journal of Work and Organizational Psychology, 8, 9-32.

Bennett, R. J., \& Robinson, S. L. (2000). Development of a measure of workplace deviance. Journal of Applied Psychology, 85, 349-360.

Bentler, P. M. (1990). Comparative fit indices in structural models. Psychological Bulletin, $107,238-246$.

Brown, M. E., Treviño, L. K., \& Harrison, D. A. (2005). Ethical leadership: A social learning perspective for construct development and testing. Organizational Behavior and Human Decision Processes, 97(2), 117-134.

Burris, E. R. (2012). The risks and rewards of speaking up: managerial responses to employee voice. Academy of Management Journal, 55, 851-875. doi:10.5465/amj.2010.0562 
Butler, H. N. \& Ribstein, L. E. (2006). The Sarbanes-Oxley debacle: What we've learned; how to fix it. Washington, DC: AEI Press.

Calhoun, C. (1989). Responsibility and reproach. Ethics, 99, 389-406.

Cohen, P., Cohen, J., Aiken, L. S., \& West, S. G. (2002). Applied multiple regression/correlation analysis for the behavioral sciences (3rd edition). Mahwah, NJ: Lawrence Erlbaum.

Deci, E. L., \& Ryan, R. M. (1985). Intrinsic motivation and self-determination in human behavior. New York: Plenum.

De Hoogh, A., \& Den Hartog, D. (2008). Ethical and despotic leadership, relationships with leader's social responsibility, top management team effectiveness and subordinates' optimism: A multi-method approach. The Leadership Quarterly, 19, 297-311.

Detert, J. R., Treviño, L. K., Burris, E. R., \& Andiappan, M. (2007). Managerial modes of influence and counterproductivity in organizations: A longitudinal business-unit-level investigation. Journal of Applied Psychology, 92, 993-1005.

Evans, M. G. (1985). A Monte Carlo study of the effects of correlated method variance in moderated multiple regression analysis. Organizational Behavior and Human Decision Processes, 36, 305-323.

Gini, A. (1998). Moral Leadership and Business Ethics. In J. B. Ciulla (Ed.), Ethics, the heart of leadership. Westport, CT: Quorum.

Grant, A. M., \& Mayer, D. M. (2009). Good soldiers and good actors: Prosocial and impression management motives as interactive predictors of affiliative citizenship behaviors. Journal of Applied Psychology, 94(4), 900-912.

Jordan, J., Brown, M. E., Trevino, L. K., \& Finkelstein, S. (in press). Someone to look up to: executive-follower ethical reasoning and perceptions of ethical leadership. Journal of Management. doi:10.1177/0149206311398136 
Kant, I. (1785/1983). Grounding for the metaphysics of morals (J. W. Ellington, Trans.). Indianapolis: Hackett.

Kanungo, R. N. (2001). Ethical values of transactional and transformational leaders. Canadian Journal of Administrative Sciences, 18, 257-265.

Lee, K., \& Allen, N. J. (2002). Organizational citizenship behavior and workplace deviance: The role of affect and cognitions. Journal of Applied Psychology, 87, 131-142.

Mitchell, M. S., \& Ambrose, M. L. (2007). Abusive supervision and workplace deviance and the moderating effects of negative reciprocity beliefs. Journal of Applied Psychology, 92, 1159-1168.

Mayer, D. M., Aquino, K., Greenbaum, R. L., \& Kuenzi, M. (2012). Who displays ethical leadership and why does it matter: An examination of antecedents and consequences of ethical leadership. Academy of Management Journal, 55, 151 - 171.

Mayer, D. M., Kuenzi, M., Greenbaum, R., Bardes, M., \& Salvador, R. (2009). How low does ethical leadership flow? Test of a trickle-down model. Organizational Behavior and Human Decision Processes, 108, 1-13.

Minson, J. A., \& Monin, B. (2012). Do-gooder derogation: disparaging morally motivated minorities to defuse anticipated reproach. Social Psychological and Personality Science,3, 200-207.

Monin, B., Sawyer, P. J., \& Marquez, M. J. (2008). The rejection of moral rebels: resenting those who do the right thing. Journal of personality and social psychology, 95(1), 7693. doi: 10.1037/0022-3514.95.1.76.

Moorman, R. H., \& Blakely, G. L. (1995). Individualism-collectivism as an individual difference predictor of organizational citizenship behavior. Journal of Organizational Behavior, 16, 127-142. 
Morgeson, F. P., \& Humphrey, S. E. (2006). The Work Design Questionnaire (WDQ): Developing and validating a comprehensive measure for assessing job design and the nature of work. Journal of Applied Psychology, 91(6), 1321-1339.

Mulaik, S. A., James, L. R., Van Alstine, J., Bennett, N., Lind, S., \& Stilwell, C. D. (1989). Evaluation of goodness-of-fit indices for structural equation models. Psychological Bulletin, 105, 430-445.

Organ, D. W. (1988). Organizational citizenship behavior: The good soldier syndrome. Lexington, MA: Lexington Books.

Podsakoff, N.P., Whiting, S.W., Podsakoff, P.M., \& Mishra, P. (2011). Effects of organizational citizenship behaviors on selection decisions in employment interviews. Journal of Applied Psychology, 96, 310-326.

Podsakoff, P. M., \& MacKenzie, S. B. (1994). Organizational citizenship behaviors and sales unit effectiveness. Journal of Marketing Research, 3, 351-363.

Podsakoff, P. M., MacKenzie, S. B., Lee, J. Y., \& Podsakoff, N. P. (2003). Common method biases in behavioral research: A critical review of the literature and recommended remedies. Journal of Applied Psychology, 88(5), 879-903.

Preacher, K., \& Hayes, A. (2008). Asymptotic and resampling strategies for assessing and comparing indirect effects in multiple mediator models. Behavior Research Methods, 40, 879-891.

Riggio, R. E., Zhu, W., Reina, C., \& Maroosis, J. a. (2010). Virtue-based measurement of ethical leadership: The Leadership Virtues Questionnaire. Consulting Psychology Journal: Practice and Research, 62, 235-250. doi:10.1037/a0022286

Rollins, B.C., \& Thomas, D. L. (1979). Parental support, power, and control techniques in the socialization of children. In W. R. Burr, R. Hill, F. I. Nye, \& I. L. Reiss (eds.), Contemporary Theories about the Family (Vol. 1). New York: Free Press. 
Sabini, J., \& Silver, M. (1982). Moralities of everyday life. Oxford: University Press.

Schminke, M., Ambrose, M. L., \& Neubaum, D. O. (2005). The effect of leader moral development on ethical climate and employee attitudes. Organizational Behavior and Human Decision Processes, 97, 135-151.

Skarlicki, D. P., \& Folger, R. (1997). Retaliation in the workplace: The roles of distributive, procedural, and interactional justice. Journal of applied Psychology, 82, 434-443.

Smith, C. A., Organ, D. W., \& Near, J. P. (1983). Organizational citizenship behavior: Its nature and antecedents. Journal of Applied Psychology, 68(4), 653-663.

Treviño, L. K., Brown, M., \& Hartman, L. P. (2003). A qualitative investigation of perceived executive ethical leadership: Perceptions from inside and outside the executive suite. Human Relations, 56(1), 5-37.

Treviño, L. K. Hartman, L. P., \& Brown, M. (2000). Moral person and moral manager: How executives develop a reputation for ethical leadership. California Management Review, 42(4), 128-142.

Tyler, T. R., \& Blader, S. (2003). The group engagement model: Procedural justice, Social identity, and Cooperative Behavior. Personality and Social Psychology Review, 7, 349-361.

Van Dijke, M. H., De Cremer, D., Mayer, D. A., \& van Quaquebeke, N. (2012). When Does Procedural Fairness Promote Organizational Citizenship Behavior?: Integrating Empowering Leadership Types in Relational Justice Models. Organizational Behavior and Human Decision Processes, 117, 235-248.

Walumbwa, F. O., Avolio, B. J., Gardner, W. L., Wernsing, T., Peterson, S. J. (2008). Authentic Leadership: Development and Validation of a Theory-Based Measure. Journal of Management, 34, 89-126. 
Walumbwa, F. O., \& Schaubroeck, J. (2009). Leader personality traits and employee voice behavior: Mediating roles of ethical leadership and work group psychological safety. Journal of Applied Psychology, 94(5), 1275-1286.

Walz, S. M., \& Niehoff, B. P. (1996). Organizational citizenship behaviors and their effect on organizational effectiveness in limited-menu restaurants. In J. B. Keys \& L. N. Dosier (Eds.), Academy of Management Best Papers Proceedings, 307-311.

Zapata-Phelan, C. P., Colquitt, J. A., Scott, B. A., \& Livingston, B. (2008). Procedural justice, interactional justice, and task performance: The mediating role of intrinsic motivation. Organizational Behavior and Human Decision Processes, 108, 93-105. 


\section{Notes}

1. Following from the curvilinear equation: $\in(y)=a x^{2}+b x+c$

The inflection point (maximum or minimum) of the graph can be calculated (x) as follows: $\mathrm{x}=\frac{-\mathrm{b}}{2 \mathrm{a}}$

2. Curvilinear effects can be sensitive to outliers in the data. We therefore scanned the data for outliers (i.e., standardized and studentized residuals $>|3|$ ) and influential cases (i.e., Cook's distances $>1$ ). Performing the analyses with or without these cases did not influence the significance or shape of the curvilinear effect in any of the three field studies.

3. An ANCOVA for deviance with perceptions of moral reproach as a covariate showed that perceptions of moral reproach was not significant, $F(1,83)=.47, p=.50$, but ethical leadership remained significant, $F(2,84)=6.61, p<.005$. Hence, moral reproach did not mediate the effect on deviance. 
Table 1

Study 1: Means, Standard Deviations and Intercorrelations

\begin{tabular}{llrrrrrrr}
\hline & & Mean & $S D$ & 1 & 2 & 3 & 4 \\
\hline 1 & Sex & - & - & & & & & \\
2 & Age & 39.23 & 10.32 & -.06 & & & \\
3 & Education & - & - & .12 & .07 & & \\
4 & Tenure & 8.30 & 8.37 & -.11 & $-.55^{\star *}$ & -.04 & \\
5 & OCB & 4.06 & .48 & $-.18^{*}$ & -.06 & .00 & -.03 \\
6 & Ethical Leadership & 3.96 & .66 & -.10 & -.03 & .08 & -.09 & .15 \\
\end{tabular}

${ }^{*} p<.05,{ }^{* *} p<.01$ 
Table 2

Study 1: Regression Results for Ethical Leadership

\begin{tabular}{|c|c|c|c|c|}
\hline & & \multicolumn{3}{|c|}{ OCB } \\
\hline \multicolumn{2}{|l|}{ Model } & Beta & $t$ & $\begin{array}{c}R^{2} \\
\text { Change }\end{array}$ \\
\hline & 1 Sex & $-.18^{*}$ & -2.11 & \\
\hline & Age & -.12 & -1.20 & \\
\hline & Education & .01 & .16 & \\
\hline & Tenure & -.10 & -1.00 & \\
\hline & Ethical Leadership & .11 & 1.31 & \\
\hline & 2 & & & $.03^{*}$ \\
\hline & Sex & $-.19^{*}$ & -2.19 & \\
\hline & Age & -.14 & -1.40 & \\
\hline & Education & .02 & .19 & \\
\hline & Tenure & -.10 & -.95 & \\
\hline & Ethical Leadership & $1.83^{*}$ & 2.14 & \\
\hline & $\begin{array}{l}\text { Ethical Leadership } \\
\text { squared }\end{array}$ & $-1.73^{*}$ & -2.02 & \\
\hline
\end{tabular}

${ }^{*} p<.05$ 
Table 3

Study 2: Means, Standard Deviations and Intercorrelations

\begin{tabular}{|c|c|c|c|c|c|c|c|c|c|}
\hline & Mean & $S D$ & 1 & 2 & 3 & 4 & 5 & 6 & 7 \\
\hline 1. Sex & -- & -- & & & & & & & \\
\hline 2. Age & 44.00 & 10.55 & $.10^{*}$ & & & & & & \\
\hline 3. Education & -- & -- & -.21 & $.22^{\star *}$ & & & & & \\
\hline 4. Tenure & 5.73 & 6.85 & .00 & $-.40^{\star *}$ & $-.18^{\star *}$ & & & & \\
\hline 5. Position & 3.68 & 2.21 & .04 & -.06 & $-.17^{\star *}$ & .05 & & & \\
\hline 6. Ethical Leadership & 2.49 & .68 & -.06 & .03 & -.07 & .08 & .02 & & \\
\hline 7. Deviance & 1.49 & .48 & $-.11^{* *}$ & $-.14^{* *}$ & -.01 & .03 & -.02 & $-.22^{\star \star \star}$ & \\
\hline 8. OCB & 2.22 & .43 & .06 & .09 & -.07 & -.08 & $.17^{\star \star}$ & $.22^{\star *}$ & -.26 \\
\hline
\end{tabular}


Table 4

Study 2: Regression Results for Ethical Leadership

\begin{tabular}{|c|c|c|c|c|c|c|c|}
\hline \multirow[b]{2}{*}{ Model } & & \multicolumn{3}{|c|}{ Deviance } & \multicolumn{3}{|c|}{ OCB } \\
\hline & & Beta & $t$ & $R^{2}$ Change & Beta & $t$ & $R^{2}$ Change \\
\hline \multirow[t]{6}{*}{1} & Sex & $-.10^{*}$ & -2.06 & & .04 & .89 & \\
\hline & Age & $.13^{*}$ & 2.31 & & .07 & 1.27 & \\
\hline & Education & .05 & .93 & & -.04 & -.84 & \\
\hline & Tenure & $-.11^{*}$ & -2.02 & & -.08 & -1.59 & \\
\hline & Position & .01 & .18 & & $.16^{\star *}$ & 3.38 & \\
\hline & Ethical Leadership & $-.17^{* *}$ & -3.57 & & $.21^{* *}$ & 4.30 & \\
\hline \multirow[t]{8}{*}{2} & & & & .01 & & & $.05^{\star *}$ \\
\hline & Sex & $-.10^{*}$ & -2.04 & & .05 & 1.00 & \\
\hline & Age & .01 & .38 & & .09 & 1.65 & \\
\hline & Education & .05 & .90 & & -.04 & -.74 & \\
\hline & Tenure & $-.11^{*}$ & -2.02 & & -.06 & -1.10 & \\
\hline & Position & .01 & .18 & & $.16^{\star *}$ & 3.41 & \\
\hline & Ethical Leadership & $-.20^{\star *}$ & -3.99 & & $.28^{* *}$ & 5.70 & \\
\hline & Ethical Leadership squared & .05 & 1.70 & & $-.24^{\star \star}$ & -4.85 & \\
\hline
\end{tabular}

${ }^{*} p<.05,{ }^{* *} p<.001$ 
Table 5

Study 3: Means, Standard Deviations and Intercorrelations

\begin{tabular}{|c|c|c|c|c|c|c|c|c|c|c|}
\hline & Mean & $S D$ & 1 & 2 & 3 & 4 & 5 & 6 & 7 & 8 \\
\hline 1. Sex & -- & -- & & & & & & & & \\
\hline 2. Age & 24.09 & 5.76 & -.00 & & & & & & & \\
\hline 3. Education & -- & -- & -.04 & $.32^{* \star^{*}}$ & & & & & & \\
\hline 4. Organization tenure & 2.34 & 2.14 & $-.17^{*}$ & $.42^{* *}$ & $.10^{*}$ & & & & & \\
\hline 5. Supervisor tenure & 1.65 & 1.59 & -.08 & $.41^{* *}$ & $.16^{*}$ & $.71^{* *}$ & & & & \\
\hline 6. Ethical Leadership & 5.19 & 1.21 & .02 & -.02 & .02 & .01 & .02 & & & \\
\hline 7. Organizational deviance & 1.79 & .92 & -.13 & -.10 & .03 & -.08 & -.06 & $-.31^{* *}$ & & \\
\hline 8. Supervisor directed deviance & 1.78 & 1.11 & $-.18^{*}$ & -.07 & -.05 & .04 & .02 & $-.30^{* *}$ & $.79^{\star \star}$ & \\
\hline 9. OCB & 5.49 & 1.22 & .08 & -.05 & -.01 & -.03 & $-.07^{\star}$ & $.37^{\star *}$ & $-.52^{\star *}$ & $-.46^{\star *}$ \\
\hline
\end{tabular}


Table 6

Study 3: Regression Results for Ethical Leadership

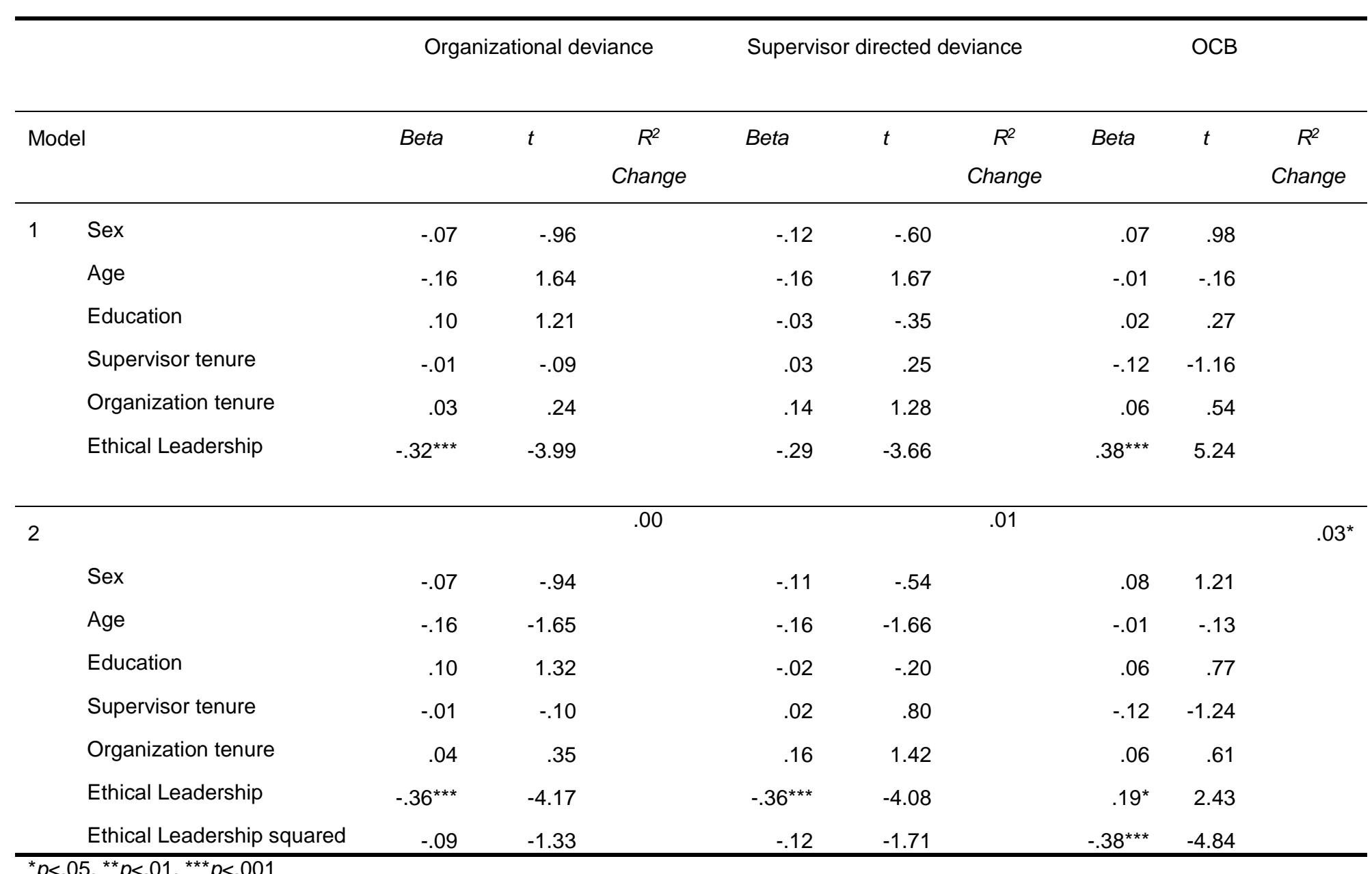

${ }^{*} p<.05,{ }^{* *} p<.01,{ }^{* * *} p<.001$ 
Figure 1: The curvilinear relation of ethical leadership and OCB in Study 1.

OCB

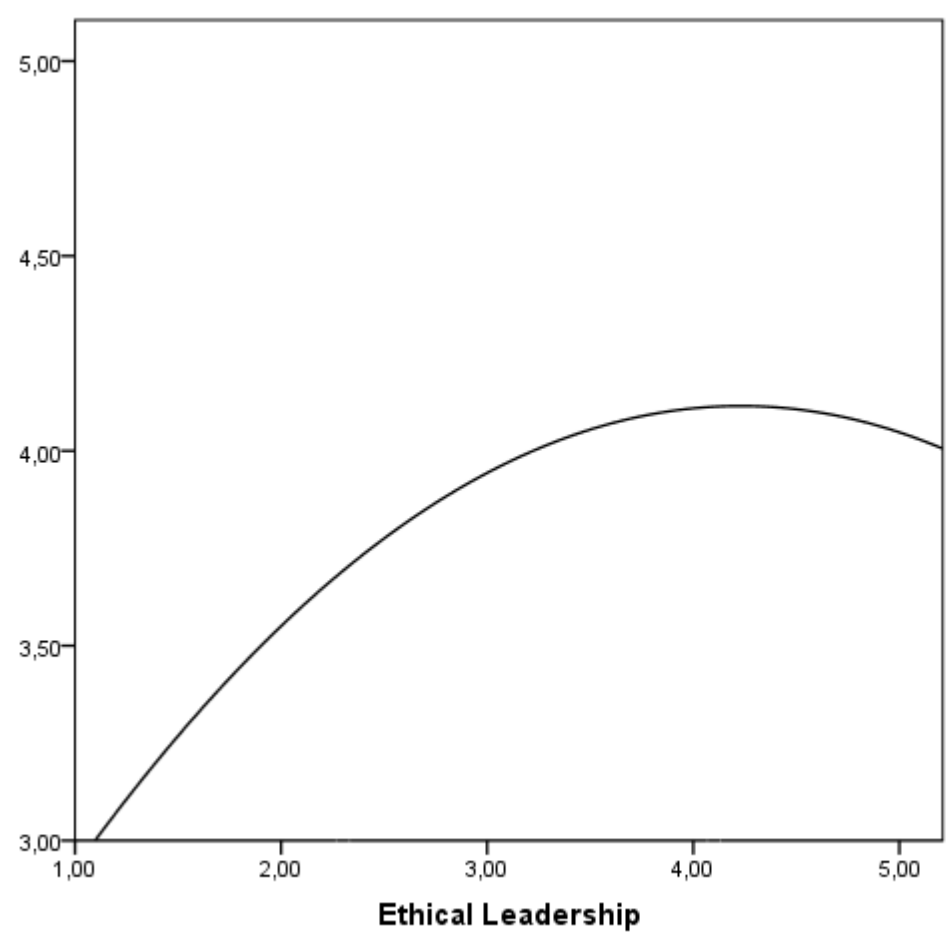


Figure 2: The curvilinear relation of ethical leadership and OCB in Study 2.

OCB

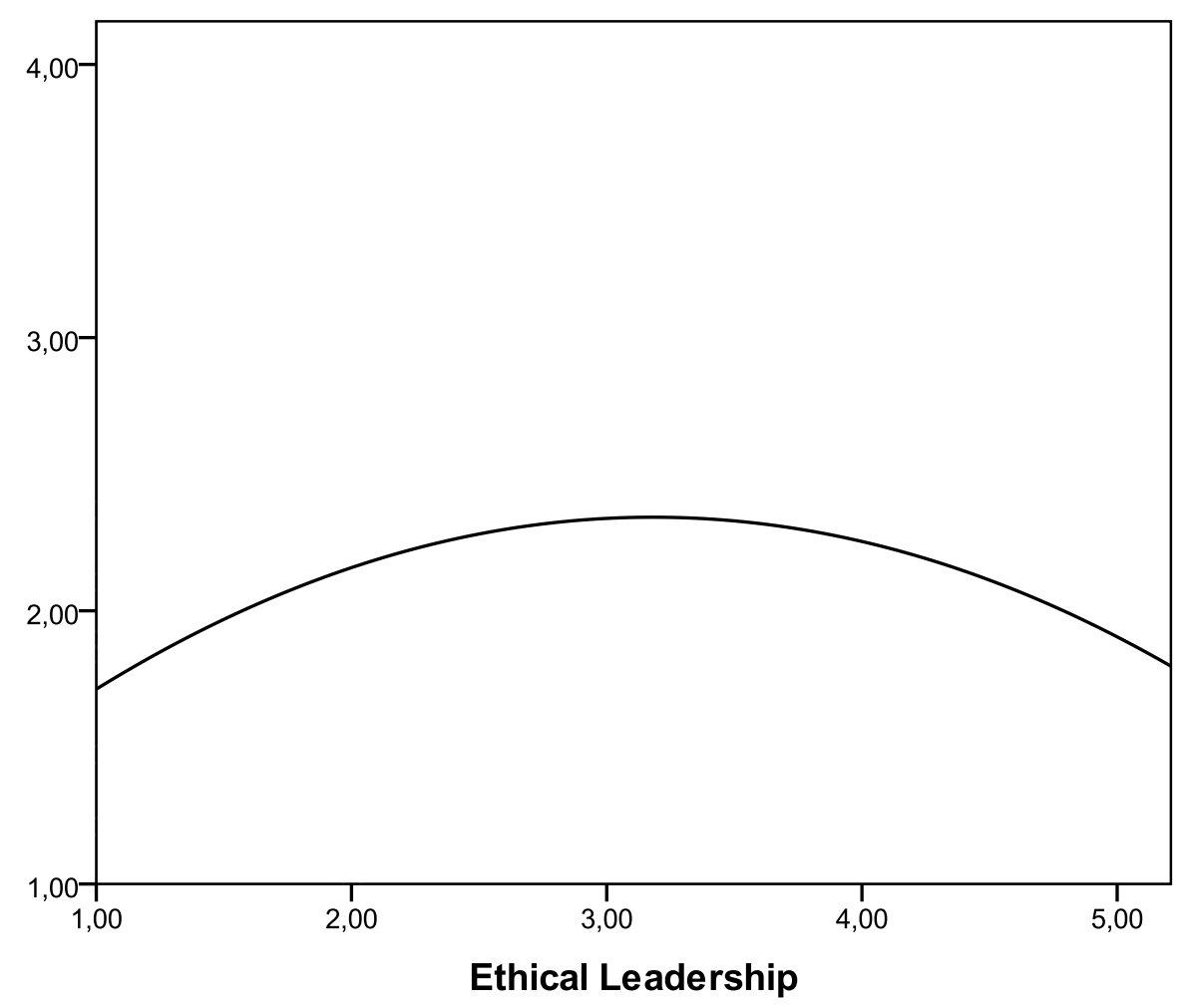


Figure 3: The curvilinear relation of ethical leadership and OCB in Study 3.

OCB

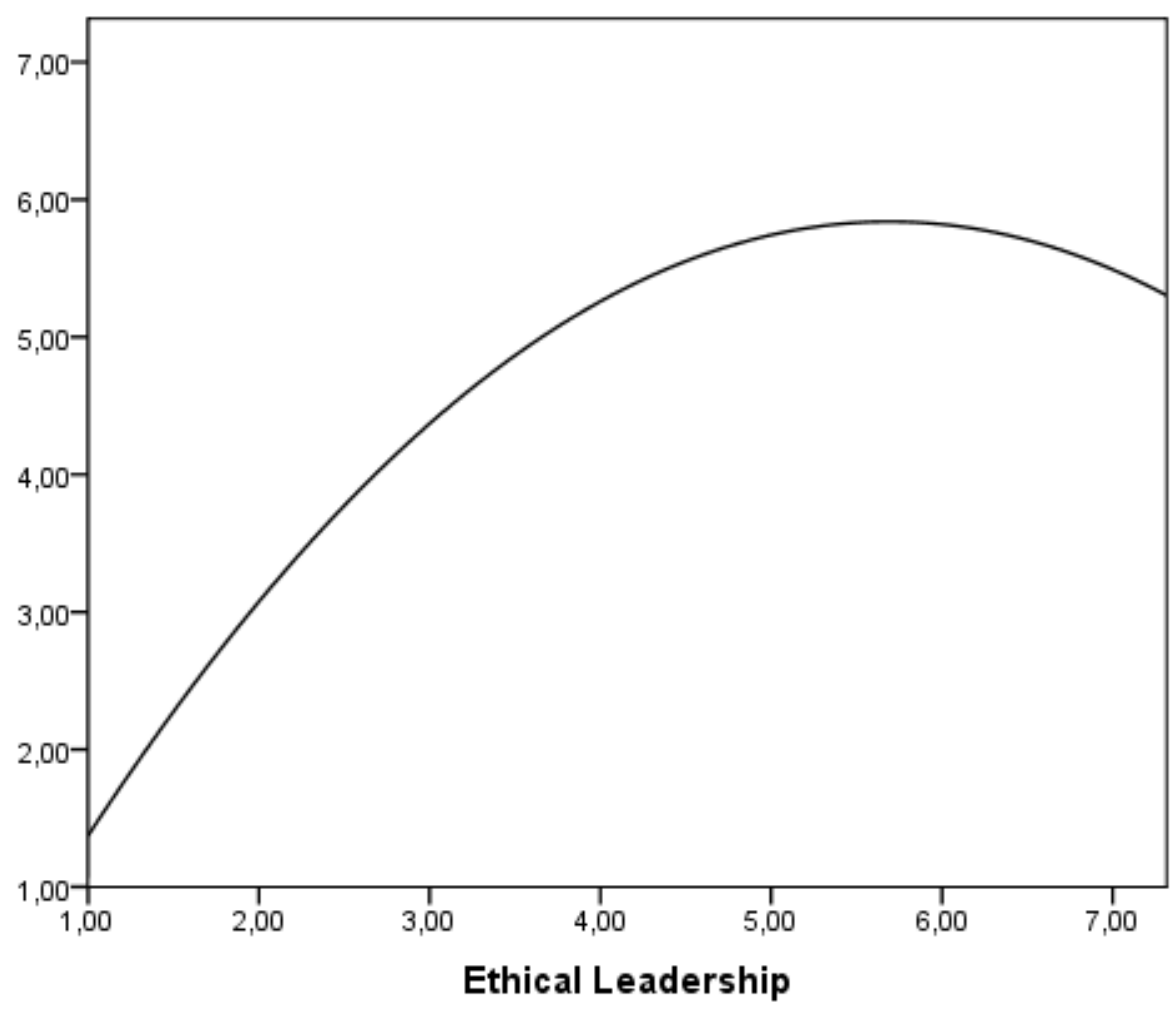

